\title{
Pengaruh Pelayanan Anak Dalam Gereja Terhadap Terwujudnya Gereja Ramah Anak Di Gereja Kemah Injil Indonesia Jemaat Tanjung Selor Kalimantan Utara
}

\author{
Mayflora Sadung, Tri Supartini
}

\begin{abstract}
Abstrak
Adapun yang menjadi tujuan dalam penulisan karya ilmiah ini adalah: Untuk mengetahui sejauh mana pelayanan anak dalam gereja berpengaruh terhadap terciptanya gereja yang ramah anak di Gereja Kemah Injil Indonesia Jemaat Tanjung Selor Kalimantan Utara. Pertama, pelayanan anak dalam gereja yaitu: kebaktian anak (sekolah minggu), merayakan hari-hari khusus, rabu gembira dan perkunjungan. Kedua, karakteristik gereja ramah anak yaitu: memerhatikan kebutuhan pertumbuhan rohani anak, menyediakan kebutuhan pertumbuhan jasmani (fisik) anak, memerhatikan kebutuhan pertumbuhan psikis anak dan memenuhi kebutuhan pertumbuhan sosial anak. Metode penelitian yang digunakan adalah metode penelitian kuantitatif untuk menjelaskan sejauh manakah pengaruh pelayanan anak dalam gereja terhadap terwujudnya gereja ramah anak di Gereja Kemah Injil Indonesia Tanjung Selor Kalimantan Utara. Hubungan sebab akibat dua variabel dengan cara mengumpulkan data yang disebarkan kepada 45 responden dan wawancara kepada guru sekolah minggu dan pemimpin gereja. Rumus yang digunakan untuk mengukur pengaruh pelayanan anak dalam gereja terhadap terwujudnya gereja ramah anak di Gereja Kemah Injil Indonesia Jemaat Tanjung Selor Kalimantan Utara adalah dengan menggunakan rumus skala Likert.

Hasil penelitian, pada karakteristik gereja ramah anak yaitu memerhatikan kebutuhan pertumbuhan rohani anak telah diterapkan dengan baik. Sedangkan karakteristik menyediakan kebutuhan pertumbuhan jasmani (fisik) anak, memerhatikan kebutuhan pertumbuhan psikis anak dan memenuhi kebutuhan pertumbuhan sosial anak masih perlu ditingkatkan. Pengaruh pelayanan anak dalam gereja terhadap terwujudnya gereja ramah anak di Gereja Kemah Injil Indonesia Jemaat Tanjung Selor Kalimantan Utara dikatakan masih perlu ditingkatkan karena pelayanan rohani lebih dominan sementara pelayanan secara fisik, psikis dan sosial belum terlalu maksimal.
\end{abstract}

Kata Kunci: Pelayanan, Anak, Gereja Ramah Anak, GKII, Holistik.

\section{Pendahuluan}

\section{Latar Belakang Masalah}

Anak merupakan manusia utuh yang diciptakan Allah, sama halnya dengan manusia dewasa diciptakan menurut gambar dan rupa Allah. Hal pertama dan terutama, anak-anak adalah tenda berkat Allah dalam Mazmur 127:3. Anak-anak adalah bagian esensial dari komunitas yang terikat perjanjian. Anak-Anak adalah penyembah. Mereka dirancang untuk 
menyembah Allah dalam Mazmur 8:2. ${ }^{1}$ Bahkan anak-anak terbukti menjadi agen pilihan untuk melaksanakan misi Allah. Anak-anak bukanlah satu-satunya pengikut, tetapi juga menjadi pemimpin yang di utus Allah dalam Yesaya 11:6. ${ }^{2}$

Melihat betapa berharganya anak-anak bagi Allah, maka seharusnya anak mendapatkan perlakuan yang baik dari berbagai kalangan terlebih khusus gereja. Gereja harus tumbuh dan berkembang menjadikan gereja yang memberikan kenyamanan dan kedamaian bagi siapa saja. Termasuk kepada anak-anak sebagai generasi penerus dan masa depan bangsa, gereja, dan keluarga. Bahkan pelayanan anak menjadi sangat penting. "Anakanak harus bertumbuh dan berkembang dengan pesat karena kasih dan kepedulian gereja kepada mereka. Gereja harus mendengarkan keinginan anak-anak dan anak-anak harus diberi kebebasan untuk mengungkapkan pandangan, kebutuhan, penderitaan, harapan dan impian."3

Allah rindu anak dalam setiap generasi mengerti betapa berharganya ia di hadapan Dia dan perlunya anak-anak itu memiliki hubungan dengan Dia melalui Yesus Kristus. Dan Allah rindu gereja-Nya menjadi saksi bagi anak-anak sehingga anak-anak mengenal dan melaksanakan kehendak-Nya dalam kehidupan. ${ }^{4}$ Yesus sendiri berkata, "Biarkanlah anakanak itu janganlah menghalang-halangi mereka datang kepada-Ku; sebab orang-orang yang seperti itulah yang empunya Kerajaan Sorga." (Matius 19:14). Gereja memiliki tanggung jawab dan mandat yang alkitabiah untuk peduli kepada anak-anak baik di dalam maupun di luar gereja. Gereja dan orangtua memiliki tanggung jawab yang alkitabiah untuk mengajar anak-anak. Dan anak-anak dapat belajar dengan jauh lebih baik dalam lingkungan yang ramah anak. ${ }^{5}$

Gereja Kemah Injil Indonesia melalui Departemen Pelayanan Anak dan Remaja yang diketuai oleh Elisabeth Selfina Ronda, MA mencanangkan sebuah proyek yaitu menjadikan Gereja Kemah Injil Indonesia sebagai gereja yang ramah anak. Proyek ini baru dicanangkan ketika ia terpilih menjadi ketua DEPARA yang sebelumnya tidak ada. Menurut beliau gereja ramah anak merupakan sebuah sistem dari gereja untuk pelayanan anak. ${ }^{6}$ Dengan adanya proyek ini, gereja seharus memberikan perhatian penuh dan pelayanan secara menyeluruh (holistic) kepada anak-anak agar gereja dapat dikatakan sebagai gereja ramah anak.

Tetapi, sehubungan dengan hal ini jika orang Kristian dewasa ditanya, "Apakah pelayanan anak dalam gereja perlu atau penting?", Dengan semangat dan lantang mereka manjawab bahwa pelayanan anak dalam gereja itu sangatlah penting karena anak-anak perlu mengenal Tuhan sejak kecil. Namun, sikap yang memandang pentingnya pelayanan anak dalam geraja itu tidak terwujud dalam kenyataannya. ${ }^{7}$ Gereja menjadikan pelayanan Sekolah Minggu sebagai pelayanan yang biasa-biasa saja sehingga tidak menggangu pelayanan orang dewasa. Karena menganggap anak-anak belum dapat mengerti dan masih terlalu kecil untuk

\footnotetext{
${ }^{1}$ Dan Brewster, Child, Church, and Mission (Panang, Malaysia: Compassion Internasional, 2011). 32. ${ }^{2}$ Dan Brewster, Child, Church, and Mission, 33.

${ }^{3}$ Tri Supartini, "Sudah Ramah Anakkah Gereja? Impementasi Konvensi Hak Anak Untuk Mewujudkan Gereja Ramah Anak" Jurnal Jaffray Vol 15, No 1 (April 2017) 10, Tri Supartini mengutip Dan Brewster, Child, Church \& Mission, 210.

${ }^{4}$ Dan Brewster, Child, Church, and Mission, 181.

${ }^{5}$ Dan Brewster, Child, Church, and Mission, 207.

${ }^{6}$ Elisabeth Selfina Ronda, Wawancara Oleh Penulis, Makassar, 6 Oktober 2017.

${ }^{7}$ Sudi Ariayanto \& Helena Erika, Menciptakan Sekolah Minggu Yang Menyenangkan (Yogyakarta: Gloria Graffa, 2005), 38.
} 
memahami Tuhan maupun pelayanan. Masih terdapat tendensi di dalam dan di luar gereja untuk mempertimbangkan bagian tertentu dari ciptaan Allah terutama anak-anak seolah-olah mereka tidak baik. ${ }^{8}$ Ketidakramahan gereja terhadap anak-anak, diperkirakan salah satu hal yang membuat anak-anak mengalami masalah dalam kerohanian. Masalah ini harus menjadi perhatian gereja mengingat anak-anak adalah generasi penerus gereja, jika hal ini dibiarkan begitu saja tentu geraja akan mengalami kemunduran atau krisis kerohanaian di masa yang akan datang.

Bila dibandingkan dengan situasi dan kondisi yang sedang terjadi di dalam pelayanan anak di Gereja Kemah Injil Indonesia Jemaat Tanjung Selor Kalimantan Utara, belum sepenuhnya memberikan perhatian kepada anak selain dari pengamatan penulis, juga dari beberapa orangtua dan pemimpin gereja (gembala dan staf) setempat menyadari dan mengakui hal ini, dan dapat dikatakan bahwa gereja ini memiliki jumlah anak yang tidak sedikit. Secara keseluruhan jumlah anak-anak yang ada kurang lebih 200 orang, namun yang aktif dalam ibadah Sekolah Minggu dan pelayanan hanya sekitar 100 hingga 150 anak. Banyak hal yang menjadi alasan bagi mereka untuk tidak mengikuti ibadah Sekolah Minggu dan salah satunya adalah bosan dan tidak menerik dengan kegiatan yang ada.

\section{Pokok Masalah}

Berdasarkan latar belakang di atas, maka yang menjadi pokok masalah dalam penulisan skripsi ini adalah: Sejauh mana pelayanan anak dalam gereja memberi pengaruh terhadap terciptanya gereja yang ramah anak di Gereja Kemah Injil Indonesia Jemaat Tanjung Selor Kalimantan Utara?

\section{Tujuan Penelitian}

Berdasarkan pokok masalah di atas, maka penulis menetapkan tujuan penulisan sebagai berikut: Untuk mengetahui sejauh mana pelayanan anak dalam gereja berpengaruh terhadap terciptanya gereja yang ramah anak di Gereja Kemah Injil Indonesia Jemaat Tanjung Selor Kalimantan Utara.

\section{Manfaat Penelitian}

Beberapa manfaat yang hendak dicapai sehubungan dengan penulisan skripsi ini sebagai berikut:

Pertama, agar karya tulis ini dapat memberkati, serta menambah wawasan penulis dan pembaca.

Kedua, agar karya tulis ini dapat dijadikan sebagi pedoman bagi penulis dalam mempersiapkan diri terjun dalam pelayanan sehingga dapat menolong gereja secara khusus pelayanan anak sekolah minggu.

Ketiga, sebagai salah satu persyaratan akademik sekolah tinggi theologia jaffray Makassar untuk mencapai gelar sarjana.

\section{Metode Penelitian}

Dalam penulisan skripsi ini, penulis menggunakan penelitian kuantitatif dengan teknik pengumpulan data sebagai berikut:

${ }^{8}$ Dan Brewster, Child, Church, and Mission, 130. 
Pertama, penulis menggunakan metode penelitian kepustakaan yaitu penelitian terhadap buku-buku yang ada kaitannya dengan pembahasan skripsi.

Kedua, penulis juga melakukan penelitian kuantitatif deskriptif dengan menggunakan populasi dan sampel serta teknik pengumpulan data melalui wawancara, dan observasi yaitu melalui angket.

\section{Batasan Penelitian}

Dalam penulisan skripsi ini, penulis membatasi diri dan menfokuskan pada suatu topik yaitu Pengaruh Pelayanan Anak Dalam Gereja Terhadap Terciptanya Gereja Yang Ramah Anak Di Gereja Kemah Injil Indonesia Jemaat Tanjung Selor Kalimantan Utara.

\section{Kesimpulan}

Berdasarkan hasil analisis pada bab sebelumnya maka kesimpulannya adalah pelayanan anak-anak sekolah minggu di Gereja Kemah Injil Indonesia Jemaat Tanjung Selor Kalimantan Utara sudah dikatakan baik dalam hal gereja melaksanankan kebaktian anak (sekolah minggu) dan merayakan hari-hari khusus. Sementara pelayanan anak untuk kegiatan rabu gembira dan perkunjungan kepada anak-anak masih perlu ditingkatkan.

Hal-hal yang dilakukan oleh Gereja Kemah Injil Indonesia Jemaat Tanjung Selor Kalimantan Utara dalam mewujudkan gereja ramah anak dapat dikatakan cukup baik. Maksudnya, untuk memerhatikan kebutuhan pertumbuhan rohani anak itu sudah dilaksanakan. Tetapi untuk menyediakan kebutuhan pertumbuhan jasmani (fisik) anak, memerhatikan kebutuhan pertumbuhan psikis anak dan memenuhi kebutuhan pertumbuhan sosial anak masih sangat perlu untuk ditingkatkan.

Pengaruh pelayanan anak dalam gereja terhadap terwujudnya gereja ramah anak di Gereja Kemah Injil Indonesia Jemaat Tanjung Selor Kalimantan Utara dikatakan masih perlu

ditingkatkan karena pelayanan rohani lebih dominan semantara pelayanan secara fisik, psikis dan sosial belum terlalu maksimal.

\section{Kepustakaan}

Ali, Mohammad. Pendidikan Kepribadian Prosedur Dan Strategi. Bandung: Angkasa, 2013.

Ariyanto, Sudi \& Helena Erika. Menciptakan Sekolah Minggu Yang Menyenangkan. Yogyakarta: Gloria Graffa, 2005.

Aziz, Safrudin. Pendidikan Keluarga. Yogyakarta: Gava Media, 2015.

Basrowi dan Sukidin. Metode Penelitian Kuantitatif. Surabaya: Insan Cendekia, 2002.

Beckwith, Ivy. Gembalakanlah Anak-anak Domba-Ku. Yogyakarta: ANDI, 2011.

Brewster, Dan. Child, Church, and Mission. Compassion Internasional, Agustus 2011.

Budiardjo, Tri. Pelayanan Anak Yang Holistik. Yogyakarta: ANDI, 2011. 
Cully, Iris V. Dinamika Pendidikan Kristen. Jakarta: BPK Gunung Mulia, 2009.

Dever, Mark. 9 Tanda Gereja Yang Sehat. Surabaya: Momentum, 2010.

Drescher, John M. Tujuh Kebutuhan Anak. Jakarta: BPK Gunung Mulia, 2009.

Dresselhaus, Richard L. Penginjilan Di Sekolah Minggu. Malang: Gandum Mas, 2003.

Harrison, Paul. Memahami Dunia Anak-Anak. Jakarta: Yayasan Komunikasi Bina Kasih/OMF, 1986.

Heath, W. Stanley. Teologi Pendidikan Anak. Bandung: Kalam Hidup, 2005.

Homrighausen, E. G., I. H. Enklaar. Pendidikan Agama Kristen. Jakarta: BPK Gunung Mulia, 2014.

Hurlock, Elizabeth B. Perkembangan Anak. Jakarta: Erlangga, 1988.

Gunarsa, Singgih D. Dasar \& Teori Perkembang Anak. Jakarta: BPK Gunung Mulia, 2012.

Kadarmanto, Ruth S. Tuntunlah Ke Jalan Yang Benar. Jakarta: BPK Gunung Mulia, 2004.

Kartono, Kartini. Psikologi Anak. Bandung: Mandar Maju, 2007.

Kilbourn, Phyllis. Children In Crisis: A New Commitment. Malang: YPPII - Dep. PAP, 2002.

Krintianto, Paulus Lilik. Prinsip \& Praktik Pendidikan Agama Kristen. Yogyakarta: ANDI, 2010.

Laster, Andrew D. Pelayan Pastoral Bersama Anak-Anak Dalam Krisis. Malang: SAAT, 2003.

Leigh, Ronald W. Melayani Dengan Efektif. Jakarta: BPK Gunung Mulia, 2011.

Lewis, Lelia. Mengajar Untuk Mengubah Kehidupan. Bandung: Kalam Hidup, n.d.

Lewis, Rodger. Karya Kristus Di Indonesia. Bandung: Yayasan Kalam Hidup, 1995.

Lie, Paulus. Mereformasi Sekolah Minggu. Yogyakarta: ANDI, 2003.

Laufer, Ruth \& Anni Dyck. Pedoman Pelayanan Anak. Malang: YPPII - Dep. PAP, 1972.

MacArthur, John. Kiat Sukses Mendidik Anak Dalam Tuhan. Jakarta: Immanuel, 2002.

Madge, Violet. Anak-Anak Mencari Arti Diri. Jakarta: BPK Gunung Mulia, 1991.

Nazir, Mohammad. Metode Penelitian. Jakarta: Ghalia Indonesia, 1985.

Naipospos, P. S. Buku Penuntun Sekolah Minggu. Jakarta: BPK Gunung Mulia, 1972.

Noya, Andy F. Autoimmune The True Story. Jakarta: Gramedia Pusta Utama, 2017.

Nuh, Nuhrison M. Agama Dan Perubahan Sosial Abad 21. Jakarta: Departeman Agama RI, Badan Litbang Dan Diklat, Puslitbang Kehidupan Keagamaan, 2008. 
Ndaraha, Roswitha \& Julianto Simanjuntak. Tidak Ada Anak Yang Sulit. Yogyakarta: ANDI, 2013.

Probo, Bayu. Saat Teduh. Jakarta: BPK Gunung Mulia, 2010.

Richards, Lawrence O. Pelyanan Kepada Anak. Bandung: Yayasan Kalam Hidup, 2007.

Ronda, Daniel. Kisah-kisah Misi Singkat Di Berbagai Belahan Dunia. Makassar: Sekolah Tinggi Theologia Jaffray, 2018.

Rudianto, Maryam. Psikologi Perkembangan Anak dan Remaja. Jakarta: BPK Gunung Mulia, 1991.

Rupp, Anne Neufeld. Tumbuh Kembang Bersama Anak. Jakarta: BPK Gunung Mulia, 2009.

Setiawan, Mary Go. Menerobos Dunia Anak. Bandung: Kalam Hidup, 2000.

Setiawan, Mary Go. Pembaharuan Mengajar. Bandung: Kalam Hidup, n.d.

Shelly, Judith Allen. Kebutuhan Rohani. Bandung: Yayasan Kalam Hidup, 2003.

Sidjabad, B. S. Membesarkan Anak Dengan Kreatif. Yogyakarta: ANDI, 2008.

Sumadikarya, Kuntadi. Mengajar Di Sekolah Minggu. BPK Gunung Mulia, 1976.

Supartini, Tri. "Sudah Ramah Anakkah Gereja? Implementasi Konvensi Hak Anak Untuk Mewujudkan Gereja Ramah Anak.” Jurnal Jaffray 15, No. 1 (April 2017): 1-30.

Ima, Sulilowati dkk. Pengertian Konvensi Hak Anak. Jakarta: UNICEF Perwakilan Indonesia, 2003

Subagyo, Andreas B. Pengantar Riset Kuantitatif dan Kualitatif. Bandung: Yayasan Kalam Hidup, 2014.

Sukarman, Timotius. Gereja Yang Bertumbuh \& Berkembang. Yogyakarta: ANDI, 2012.

Suryanah. Keperawatan Anak Untuk Siswa SPK. Jakarta: Penerbit Buku Kedokteran EGC, 1996.

Ukur, Fridolin. Tuaiannya Sungguh Banyak. Jakarta: BPK Gunung Mulia, 2002.

Usman, Husaini dan Akbar, Purnomo Setiady. Metode Penelitian Sosial. Jakarta: Bumi Aksara, 1996.

Walgito, Bimo. Pengantar Psikologi Umum. Yogyakarta: ANDI Offset, 1999.

Wijanarko, Jarot. Anak Di Mata Tuhan. Jakarta: Suara Pemulihan, 2006.

Wijaya, Hengki. Ed. Metodologi Penelitian Pendidikan Teologi. Makassar: Sekolah Tinggi Theologia Jaffray, 2016.

Yahya, Ayub. Titik Nol: Saat Pendeta Tak Di Mimbar. Jakarta: BPK Gunung Mulia, 2008. 